\title{
Considerations regarding the effectiveness of Risk Management for Internal Managerial Control System
}

\author{
Cosmin FILIP \\ PhD Student, The Bucharest University of Economic Studies, Bucharest, Romania \\ filip.cosmin@univ-ovidius.ro
}

\begin{abstract}
The paper presents a systemic analysis of the key factors of risk management for the internal managerial control (IMC) system for public entities in Romania. The risk management approach offers a broad view regarding the necessary tasks for having a rigorous, efficient, effective and transparent use of public funds. The necessity of taking a managerial decision on a current matter has its own peculiarities and effects, involving the actual way and manner in which the entity in question will go further. The effects of this kind of decisions can affect the entity in some precise moments. In this point, risk management should be present, according to the applicable approaches, in order to evaluate, among other things, the vulnerability of the system which is exposed to the effects of a decision that has been taken into account. Developing an internal control system is perceived as a process that involves improving performance and governance, rather than introducing a new, additional system. The paper is presenting some considerations regarding the effectiveness of risk management approach used in Romanian public entities, based on the latest reports published. There are also pointed out some principal causes for this implementation level of Risk management Standard, along with some selective proposals for improving the results of this risk based approach
\end{abstract}

Keywords: internal managerial control system, public entities, risk management, managerial decision, system vulnerability.

\section{Introduction}

Internal managerial control (IMC) is a dynamic and integrated process of permanent adaptation of the public institution to changes that take place in the external environment.

The IMC approach actually represents a specific manner of analyzing the institution's activities. This way, by adopting and applying a new type of internal management that is frequently associated with the knowledge activity, it allows the top management of the public institution to coordinate its activities in a more efficient way. That is why internal control has to be considered as a managerial function and not as a verification operation. This is not just a general notion, a doctrine or a multitude of reports and tables to be completed, but a set of methods, through which a public entity can be managed, capitalizing on the most appropriate ways for organizing the activities carried out.

In Romania, the IMC system which is applied for public entities is regulated mainly by RGGS (2018) and RGGS (2019). According to RGGS (2018), the design, implementation and continuous development of a viable IMC system are possible only if the system complies with the following requirements:

- to be adapted to the size, complexity and specific environment of the entity, according to its object of activity;

- to cover all levels of management and all activities/operations from the organization and also from the internal regulations applied, management system, staff structure, the relationships established and recognized at different organizational levels;

- to be built on the same tools in all public entities: objectives, means, informational system, organization, procedures, control; 
- to provide reasonable assurance that the entity's objectives will be met - the design of all activities in terms of objectives, the establishment of resources, the responsibilities and the manner of achievement.

- the costs of applying the internal control system have to be lower than the benefits resulting from it;

- to be governed by the minimum management rules contained in the Internal Managerial

PICBE $\mid 665$ Control Standards.

IMC standards imply through the management requirements that all public entities have to implement them for rigorous, efficient, effective and transparent use of public funds. The goal of these control standards is to generate a solid IMC model that can be used to highlight the results of the entity and its evolution. This IMC package of standards legislated by RGGS (2018) contains 16 standards grouped into 5 reference categories.

One of the main Standards that is included in the IMC package of standards is Risk management (Standard no. 8). The expected results of Risk management standard are targeted to point out the manner in which the public entity is dealing with the incertitude of the achievement of the proposed objectives. So, the role of this Risk management approach proposed through this Standard is to be an important tool through which an efficient and effective IMC system should be implemented at any public entity level.

In this context, the current study is proposing a holistic analysis of the effectiveness of risk management for IMC system in Romanian public entities. Thus, starting with the latest report published in august 2019 by DCIMRI (2019) on the IMC implementation in Romanian public entities, the paper's aim is to point out the issues identified in the implementation practice of Risk management standard. The paper presents some considerations regarding the causes of this problematic level of risk management implementation and gives some indications on the improvement measures that have to be included in this risk based approach.

\section{Literature review}

In Romania, the IMC is regulated by the national legislation. The legal authority on IMC regulations is the Internal Managerial Control and Interinstitutional Relations Department from the Romanian Government's General Secretariat (DCIMRI). According to RL 174 (2015), its mission is to support the Romanian public entities for the implementation and development of the internal managerial control system, to regulate the instruments that compose it, and also to respond as well as possible to the need of public entities' management in order to effectively control their own activities.

On the subject of Risk management approach, the international literature is quite extensive with a multitude of different domains in which this approach is used. An important landmark on this approach is the COSO (2017) which is presenting an updated vision of enterprise risk management that contains certain strategy and performance requirements. For internal control systems, a comprehensive assessment model for enterprise risk management has been proposed by Dittmeier, C., et al., (2014). The most comprehensive point of view regarding the Risk assessment techniques is presented in ISO/IEC 31010 (2019).

Regarding the Risk management approach for Romanian IMC system, the requirements for public entities are presented in RGGS (2018). There are also some methodologies published across time to support this approach. The core of the methodological guide that was published in Romania 
is the one prepared by MFP (2007), based on the past edition of ISO 31000 (2018). The latest risk management methodology that contains references for IMC system was published by SGG (2018).

\section{Methodology}

Related to the responsibilities involved, the public entity should provide adequate responsibility, a clear level of authority and sufficient competence to support the risk management process. It must be taken into account that the risk management implementation process must ensure the adequacy, the effectiveness and the efficiency of any controls that are being used. The risk management procedures which are developed by any public entity are recommended to be incorporated in all processes from any organizational level in order to be relevant, effective and efficient.

A Risk management approach that is used in a public entity regarding the IMC standard for Risk management involves two levels of hierarchy. One refers to the organizational structure of the public entity as a development framework for risk management activities. The second level refers to risk assessments activities on a project or department level. These two points of view are complementary and both of them are based on the application of solid principles regarding risk management approach. In Fig. 1 are presented the relations between the risk management principles, the organizational framework for managing risk and the process of managing risk.

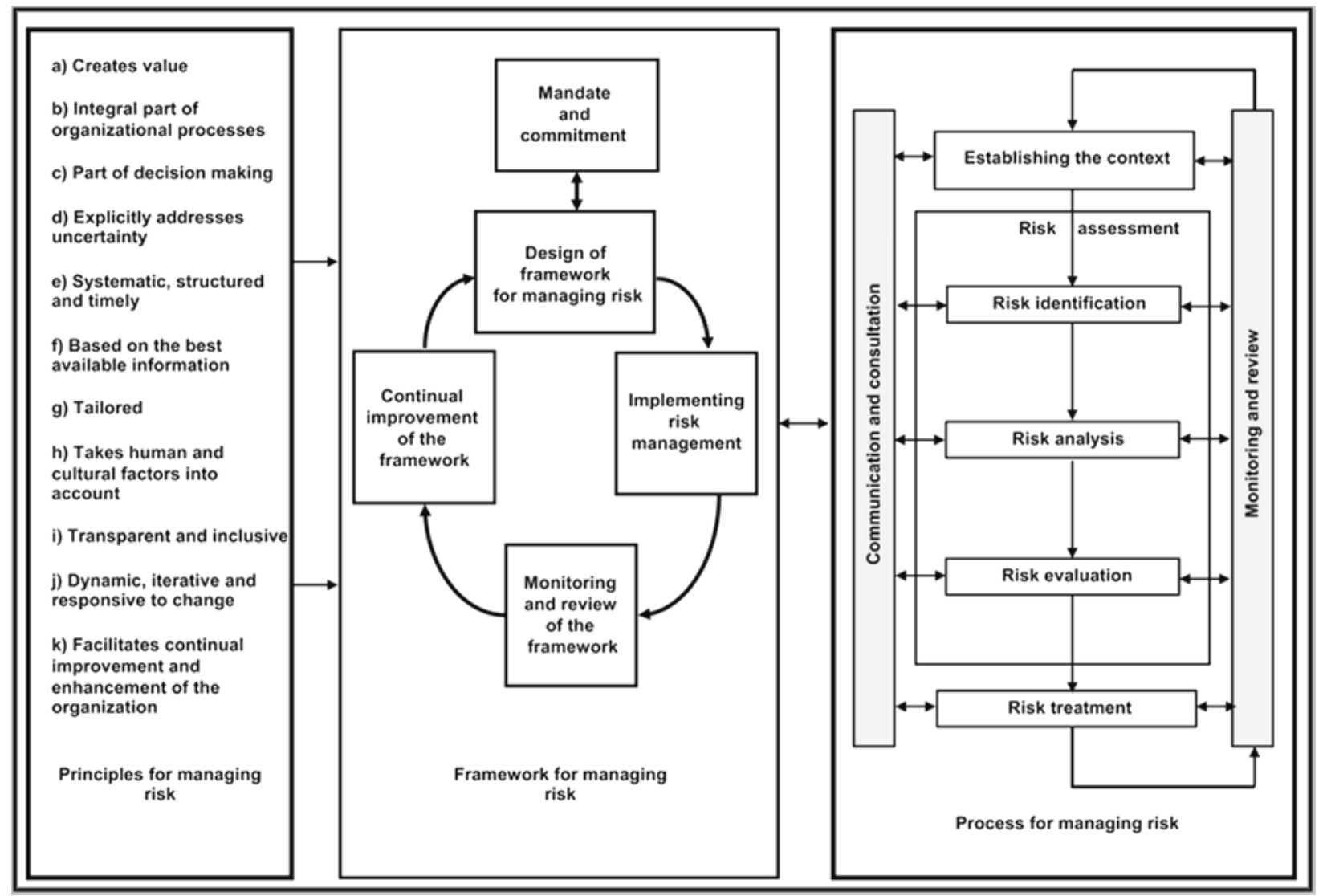

Figure 1. Relations between the risk management principles, organizational framework and process for managing risk

Source: ISO 31000 (2018). 
Risks can be assessed at an organizational level or at a departmental level, for projects, individual activities or specific risks. The Different tools and techniques that are appropriate depend on the given contexts.

The paper is focusing on the use of the principles for managing risk in order to prepare the risk management approach for the use in the IMC system. Some considerations regarding the effectiveness of risk management for IMC system are included.

PICBE | 667

Each public entity has to handle the risk management approach with the resources that are available. It is not convenient to point out what a public entity does not have in order to cover the deficiencies from the risk management approach. The best results must be obtained with the existing resources. And in time, the development of the risk management activities has to be based on the development of the common resources. „It doesn't matter how many resources you have. If you don't know how to use them, they will never be enough" (Anonymous). This saying is applying perfectly here, where more or less resources are available and the result should be proportional and needs to be increasing step by step.

It is clear that a risk analysis cannot completely eliminate the risk of the decision that needs to be taken, but it can give the public's entity top management the ability to:

- decide whether or not the risk is acceptable;

- know the decisions' consequences, both positive and negative;

- reduce the risks taken into account through control measures.

Risks must be identified and managed at any level where it is considered that there might be disruptions in the entity's achievement of objectives.

In the cases without any previous analysis done, a single measure is established on site, usually the first one that is identified. Possible management measures need to be identified and the appropriate ones need to be selected (it can be a set of measures) based on risk appetite, costs involved, existing possibilities and other specific circumstances. So, multiple risk responses can always be established.

Risk management should also be applied for the following reasons:

- as a manager it is easier to prevent than to treat;

- better decisions can be taken because they are based on assessed risks and not on intuition;

- it is a tool that can be used for an uncertainty approach, that is addressing to what might happen in the future, preparing therefore the public entity for the next problems which could appear;

- it is based on previous experiences that were gained from past actions, in order to not persist in making the same mistakes.

The risk management process requires the involvement of all factors, both those with management positions and also those with executive responsibilities within the public entity. Clear responsibilities must be established at all organizational levels and it's also decisive to have functional decision-making structures.

The contribution of the internal audit to the processes of governance, risk management and control of the organization is particularly important. The involvement of the public internal audit department in the risk management process is achieved through:

- independent assessments, advisory and guiding missions to ensure correct identification and risk management; 
- audit missions, which should compensate the process of reviewing and reporting the risks based on self-assessment subjectivity.

It is very important for each employee to be aware about the usefulness and the necessity of the risk management process applied in the current activity and also about the implications it can have on the entity's objectives fulfilment.

An efficient risk management process for the main credit release authority must also take into account the quality of the risk management approach of the institutions under its coordination/subordination/authority which are also contributing to the achievement of the objectives for the respective public entity.

\section{Results and discussions}

The consolidation of the internal managerial control system depends on the quality of Risk Management standard implementation. In Table 1 are presented the comments for Standard no. 8 - Risk management.

Analyzing the results of the RGGS (2018) report, it is clear that the implementation of IMC activities is perceived as an additional activity to the job-specific responsibilities.

Table 1. Expectations to be met, expected results \& comments on Standard no. 8 - Risk management

\begin{tabular}{|c|c|c|c|}
\hline No. & \begin{tabular}{|} 
EXPECTATIONS \\
TO BE MET - as \\
presented in \\
RGGS (2018)
\end{tabular} & & COMMENTS \\
\hline 1 & $\begin{array}{l}\text { Identification and } \\
\text { assessment of } \\
\text { risks related to } \\
\text { the objectives / } \\
\text { activities }\end{array}$ & $\begin{array}{l}\text { the risks related } \\
\text { to the objectives / } \\
\text { activities were } \\
\text { identified and } \\
\text { evaluated }\end{array}$ & \multirow{3}{*}{$\begin{array}{l}\text { Risk management can be the main approach regarding the safety of } \\
\text { the objectives' accomplishment. It has to be considered as an active } \\
\text { tool for public entity in order to analyze the disturbing factors that } \\
\text { can affect the meeting of the objectives. } \\
\text { The head of the public entity has to organize and to implement a } \\
\text { solid risk management process that facilitates the objectives' } \\
\text { achievement in terms of economy, efficiency and effectiveness. } \\
\text { To achieve useful results, risk management policies must include a } \\
\text { risk register in which all important information about risk events that } \\
\text { may occur should be written. This register must be completed after } \\
\text { the risk assessment stage. } \\
\text { When necessary, the coordination with other activities is important } \\
\text { to be followed with all the good or bad aspects related, ensuring that } \\
\text { the current risks and any other particular threats are taken into } \\
\text { account in each similar situation. } \\
\text { Based on monitoring and assessment risk approach, decisions should } \\
\text { be taken for the improvement of risk management policies applied. } \\
\text { For the public entity, these decisions should lead to an improved risk } \\
\text { management approach and to an upgraded risk management culture. }\end{array}$} \\
\hline 2 & $\begin{array}{l}\text { Establishment } \\
\text { and monitoring } \\
\text { control measures } \\
\text { related to } \\
\text { significant risks }\end{array}$ & $\begin{array}{l}\text { control measures } \\
\text { related to } \\
\text { significant risks } \\
\text { were established } \\
\text { and monitored } \\
\end{array}$ & \\
\hline 3 & $\begin{array}{l}\text { Annual reporting } \\
\text { on risk } \\
\text { management } \\
\text { process which } \\
\text { contains the risks } \\
\text { analysis. }\end{array}$ & $\begin{array}{l}\text { The analysis of } \\
\text { identified and } \\
\text { managed risks is } \\
\text { materialized } \\
\text { through an annual } \\
\text { report on the risk } \\
\text { management } \\
\text { process. }\end{array}$ & \\
\hline
\end{tabular}

Source: Authors' own research[

Regarding the risk management process, the awareness of the entity's staff is still at a low level, its usefulness and necessity not being understood well enough for the wellbeing of the public's entity current activity.

So, some of the main dysfunctions that are causing and contributing not to meet the expectations regarding the IMC Standard no. 8 full implementation, are presented below: 
- there is no risk management approach applied to the public entity, or an incipient one;

- the problems are, in general, solved on site, without major/minimum previous analyses;

- no proactive approach is applied to the public entity for the activities carried out;

- there are only reactive measures established on site;

- there is no risk identification in the public entity related to objectives/activities/ results;

- there is no risk assessment in the public entity related to objectives/activities/results;

- no risk is monitored in the public entity activities;

- there are no control measures related to significant risks;

- there are no reports on risk management process;

- the risk management reports do not include the risk register;

- annual reports on risk management process do not contain the risks analysis;

- annual reports on risk management process contain only risks identification;

- there are, from time to time, partial reports on risk management process.

In order to perform a substantiated risk analysis, but also to reduce the subjectivity degree of the risk analysis, it is necessary to use well-defined risk analysis criteria. These criteria that are taken into account should include sufficient information and the necessary details regarding the effective manner of performing the risk analysis and the establishment of risk score or the risk classification. Unfortunately, there are only few cases in which public entities have developed a clear and useful system adapted to that public entity for specific risk analysis criteria.

So, it is recommendable that a proactive management approach should be adopted. This means that it is necessary to design and implement some measures that are focused on possible risks identification before risks materialization and before producing unfavorable consequences on the objectives and on activities that have been set. On the other hand, by applying a proactive management it must be establish a balance between excessive risk and oversized control.

Other causes that are affecting the result of risk management approach that should be analyzed in order to increase the implementation accuracy can be considered the next ones:

- the needs for professional training in the field of risk management have not been identified;

- the risk management process is not functional;

- the steps related to the risk management process have not been completed chronologically and successively, which led to an inadequate treatment of the risks identified;

- the activities regarding the identification, evaluation and response to risk are not based on a system procedure regarding risk management that is related to public entity needs;

- there is no staff responsibility regarding the risk management activities that need to be done, by not mentioning the specific attributions regarding the Risk Management in the job descriptions;

- the risk assessment and the classification of the type of risk response are not in accordance with internal procedures;

- the confusion created between the risk and the cause that generated its occurrence, as well as in the ranking and the prioritization of risks treatment;

- the risk registers used by public entities are incomplete and are not updated on the format established to be used.

Expressing the analyzed risks through risk exposure leads to the achievement of public entity risk profile. For a public entity, this risk profile is unique and personalized from the perspective of 
the objectives, the activities carried out and the general context. There is no risk profile for the same type of public entities, thus being particular for each one.

For achieving a coherent risk management, the process implies:

- a prior analysis of the exposure for the risk taken into consideration, since the identification of the risk sources is a fundamental and a decisive step towards a correct risk assessment for the public entity;

PICBE | 670

- identifying risks that may affect the effectiveness and efficiency of activities related to specific objectives, without ignoring the rules and regulations;

- confidence in the financial information and in the management strategy applied;

- protection of goods, respectively prevention and detection of fraud;

- defining the acceptable level of risk exposure and the level of risk tolerance;

- assessing the probability of risk materialization, determining the risk impact and the risk exposure to risk;

- establishing the type of risk response and the adopted strategy mapping.

The impact of a risk can target the qualitative component, the patrimonial-budgetary component, effort component (human resources) and time component, depending on the risk tolerance proposed. Establishing the risk tolerance limit is the responsibility of the entity's manager and has implications for the costs associated with the control measures.

In connection with the risk tolerance, the risk tolerance limit is established, which is a limit that is analyzed from the following perspectives:

- Cost-benefit perspective - the purpose of this analysis is to determine whether the proposed tolerance limit does or does not involve excessively high "costs" in relation to the benefit;

- Total resources perspective - which the public entity can allocate to be used in applying control measures. If resources are insufficient, there is a ranking made of risks according to public entity priorities and also a readjustment of tolerance limits for less priority risks.

An important part of the identified risks is caused by non-compliance with the existent procedures, and in some cases the circumstances that favor their occurrence are even the result of an inadequate control of the activities. In general, too many risks are due to lack of procedures. The ignorance or ambiguity of some rules is often invoked as an explanation for the failure. It is the manager's obligation to clarify what needs to be done and how it needs to be done by those involved, without leaving room for subjective interpretations.

It is recommended to develop-a system procedure based on a risk management approach that is applied on public entity. The procedure must be designed so that it can be used by all the departments within the public entity in order to manage the risks that may affect the achievement of the specific objectives of those departments. Its role would be to provide to the public entity's staff a functional working tool to support the risk managing activities through a methodical and efficient way, in order to meet the public entity's objectives. This ensures the continuity in time of the risk management process, even in staff fluctuations conditions.

For an efficient risk management, each department manager from the first management level of the public entity has to appoint through internal decision the person in charge with risk managing. This person also assists him in the risk management approach applied for the public entity. The Department Risk Manager is in charge with the staff advising activities within the Risk Management approach. 
The action plan represents the activities that must be carried out to achieve the objectives. Through a risk management approach, this plan must be doubled by the risk mitigation plan. From the perspective of risk management, achieving the objectives means:

- to plan the activities and actions that must be carried out in order to achieve the proposed objectives (plan A);

- to plan the internal control actions that are necessary to manage the risks and to integrate

PICBE | 671 these actions into the general activities plan (plan B);

- to plan the actions to be taken if the risks are materializing (plan $\mathrm{C}$ ).

All these 3 plans are the essential elements of an effective general management approach which also integrated a risk management approach.

It is necessary to ensure a favorable and adequate information framework to inform all staff about the risk management process by creating an intranet section in which experiences are presented and communicated to those who can benefit from them.

The risk management process has a special importance and a high impact on the fulfilment of the public entity's objectives. For this, it is required an adequate protection regarding the access of unauthorized persons from the external environment

\section{Conclusion}

The intent of this analysis was to highlight the risk management approach from the effectiveness perspective, analyzing the causes that are generating the current implementation level for Romanian public entity, which can be considered low.

The paper also presented some of the main dysfunctions that can be considered the most important reasons for the lower implementation degree of Risk management standard in the IMC system approach. In the same time/furthermore, some considerations have been expressed regarding the aspects that need to be taken into account for an improvement of applied risk management practices.

So, in order to have an efficient risk management and to avoid an excessive and uncontrolled volume of risks to handle, it is important for the public entity to manage only the risks that are really affecting its objectives.

It can be concluded that in the risk management process implementation, both management and executive staff have to:

- understand how much and the manner in which the risks affect the public entity, leading to risk identification and risk assessment;

- gather information about the risks - the necessity to target the scope to collect data about the sources and factors that generate each risk;

- to allocate adequate resources for risk management;

- to analyze the risks' effects by assigning responsibilities in this matter;

- disseminate good practices among public entity personnel and to inform all departments about the risk reduction possibilities.

In order to consolidate and develop the risk management process, it is recommended for public entities to share good practices in the field, especially if the public entity is subordinated to other institutions.

We can conclude by saying that an efficient risk management implies that the entire risk management process needs to be a permanent one and to ensure the connection of the public entity to the constant change and therefore adaptation process that is necessary. On the other hand, 
handling too many risks leads to an important decrease in the applicability of the risk management process, diluting the essential part.

Every public entity has to define its own strategy in terms of risk procedure for the risks that it might face with and needs to make sure that the strategy is fully and adequately documented.

\section{References}

International Organization for Standardization - ISO 31000 (2018), Risk management. Principles and guidelines, Geneva, Switzerland

International Organization for Standardization - ISO Guide 73 (2009), Risk Management. Vocabulary, Geneva, Switzerland

International Organization for Standardization - ISO/IEC 31010 (2019), Risk management. Risk assessment techniques, International Electrotechnical Commission, Geneva, Switzerland

Romanian Government's General Secretariat - RGGS (2018). Order no. 600/2018 for the approval of the Code of internal managerial control of public entities, published in the Official Journal of Romania, Part I, Nr. 387, 07.05.2018.

Romanian Government's General Secretariat - RGGS (2019). Order no. 1054/2019 for the approval of Methodological Norms regarding the coordination, the methodological guidance and the supervision of the implementation and development stage of internal management control system for the public entities, published in the Official Journal of Romania, Part I, Nr. 847, 18.10.2019.

Romanian Law no. 174 - RL 174. (2015) for the approval of the Government Emergency Ordinance no. $86 / 2014$ regarding the establishment of reorganization measures at the level of the central public administration and for the modification and completion of some normative acts, with subsequent amendment, published in the Official Journal of Romania, Part I, no. 475 of June 30, 2015.

Internal Managerial Control and Interinstitutional Relations Department from the Romanian Government's General Secretariat - DCIMRI (2019) - Report on internal managerial control for 2018, published on September 2019, Retrieved from https://sgg.gov.ro/new/wpcontent/uploads/2019/09/Raport-SCIM-2018.pdf

Dittmeier, C., Casati, P., (2014). Evaluating Internal Control Systems - A Comprehensive Assessment Model (CAM) for Enterprise Risk Management. The Institute of Internal Auditors Research Foundation, Florida, Retrieved from https://www.interniaudit.cz/download/IIA/Evaluating-Internal-Control-Systems.pdf

Government's General Secretariat - SGG (2018). Risk management methodology, Retrieved from https://sgg.gov.ro/new/wp-content/uploads/2018/07/Metodologia-de-management-alriscurilor-2018.pdf

Ministry of Public Finance - MFP (2007). Methodology for implementing the internal control standard "Risk management", Retrieved from http://discutii.mfinante.ro/static/10/Mfp/control_prev/manuale/METOD_IMPLEMENTA RE_RISC.pdf

Committee of Sponsoring Organizations of the Treadway Commission - COSO (2017). Enterprise Risk Management Integrating with Strategy and Performance, Retrieved from https://www.coso.org/Documents/2017-COSO-ERM-Integrating-with-Strategy-andPerformance-Executive-Summary.pdf 